\title{
Addressing bias in industry-funded CME
}

$\mathrm{E}$ mails describing continuing medical education (CME) programs pop up on Dr. Brian Gilfix's computer all the time, and though industry sponsorship of CME is not uncommon, there were several things about a program description that recently crossed his inbox that struck him as rather egregious.

The program was about testing for metal hypersensitivity, a controversial subject, says Gilfix, an associate professor of medicine at McGill University in Montréal. Yet the document he was reading lacked balance; it appeared closer to promotion than education. Furthermore, if you clicked on the URLs listed under "resources," you were taken to corporate websites, where you learn that the cost of testing starts at $\$ 450$.

"They had direct links to the testing company, and that company had a proprietary test; that struck me as a bit much," says Gilfix.

There is much money to be made, in industry-sponsored CME and conflicts of interest abound, a situation that is often accepted, if begrudgingly, and somewhat controlled by disclosure rules and processes to reduce bias.

Some physicians, however, feel the continuing education of doctors is too important to be influenced by the bias, overt or subtle, that inevitably creeps into programs sponsored by industry. They suggest that industry-funded CME focuses too much on some topics, like prescribing brand-name drugs, and too little on other subjects, like diet, generic medications or improving communication.

"I think that is a huge issue," says Dr. Sheryl Spithoff. In a recent editorial in Canadian Family Physician, Spithoff, who practises at Women's College Hospital in Toronto, delves into some of the problems with industry involvement in CME. For example, it places CME organizers under pressure to create content and choose speakers that will attract industry funding. Pharmaceutical sponsorship has also been linked to poorer prescribing habits, including nonadherence to guidelines and overprescribing of expensive, brand-name drugs.

Spithoff cites the sponsorship of more than 20000 educational programs for the opioid OxyContin as a cautionary tale. Sales of the drug in the United States grew from \$48 million in 1996 to almost $\$ 1.1$ billion by 2000 , but the risks of addiction and abuse were misrepresented in educational material for physicians, writes Spithoff.

In the US, industry support for CME grew from $\$ 301$ million to $\$ 1.2$ billion between 1998 and 2007, according to a paper in the New England Journal of Medicine. Industry sponsorship appears to have peaked around 2007, however, and declined by $31 \%$ by 2010 . This

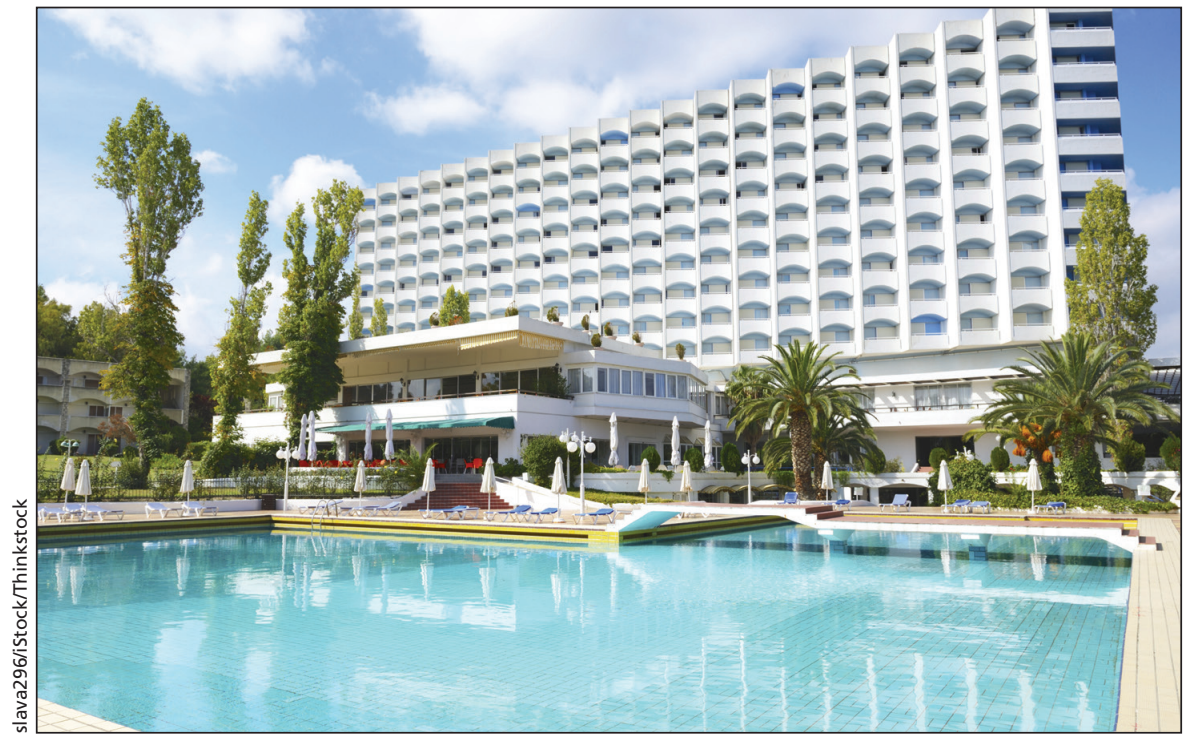

How can you afford CME without industry money? Tip: don't host programs at venues that look like this. decline has been attributed, in part, to increased scrutiny, which led to increased restrictions on conflicts of interest at some institutions and, in several cases, bans on industry funding.

"There is still a tonne of money sloshing around, though," says Dr. Michael Steinman, an associate professor of medicine at the University of California, San Francisco, and the paper's lead author.

In an earlier editorial in Canadian Family Physician, Steinman argued that financial dependency on industry can have "subtle yet strong effects" on the objectivity of educational programs.

Spithoff writes that ideally industrysponsored CME should be banned, but at the very least it should be limited by permitting companies to contribute to an unrestricted pool rather than to individual sessions. She also recommends that the colleges that accredit CME programs implement five-year plans to only accredit sessions that have received no money from industry. Moving toward prohibiting physicians with financial ties to industry from planning or teaching CME would also be a step in the right direction, writes Spithoff.

Alternate sources of funding suggested for CME include increased fees for physicians, a tax on the pharmaceutical and medical device industries and funding from the public health care system.

According to Steinman, industry influence could be mitigated if CME providers went beyond minimum accreditation standards. They could, for instance, decline to offer events sponsored by a single company. As for how to pay for CME, minimizing costs would be a good place to start, says Steinman. "You can convene a CME conference in a hospital or university facility where you can get an auditorium or conference room at low or no cost, as opposed to doing it in a fancy hotel." - Roger Collier, CMAJ

\section{CMAJ 2014. DOI:10.1503/cmaj.109-4918}

This is part 1 of a series on continuing medical education. Find part 2, "CME accreditation: separating education from promotion," at cmaj.ca 